\title{
Mechanisms of disturbed emotion processing and social interaction in borderline personality disorder: state of knowledge and research agenda of the German Clinical Research Unit
}

\author{
Christian Schmahl ${ }^{*}$, Sabine C Herpertz ${ }^{2}$, Katja Bertsch² ${ }^{2}$ Gabriele Ende ${ }^{3}$, Herta Flor ${ }^{4}$, Peter Kirsch ${ }^{5}$, Stefanie Lis ${ }^{1}$, \\ Andreas Meyer-Lindenberg ${ }^{6}$, Marcella Rietschel ${ }^{7}$, Miriam Schneider ${ }^{8}$, Rainer Spanagel ${ }^{8}$, Rolf-Detlef Treede ${ }^{9}$ \\ and Martin Bohus ${ }^{1}$
}

\begin{abstract}
The last two decades have seen a strong rise in empirical research in the mechanisms of emotion dysregulation in borderline personality disorder. Major findings comprise structural as well as functional alterations of brain regions involved in emotion processing, such as amygdala, insula, and prefrontal regions. In addition, more specific mechanisms of disturbed emotion regulation, e.g. related to pain and dissociation, have been identified. Most recently, social interaction problems and their underlying neurobiological mechanisms, e.g. disturbed trust or hypersensitivity to social rejection, have become a major focus of BPD research. This article covers the current state of knowledge and related relevant research goals. The first part presents a review of the literature. The second part delineates important open questions to be addressed in future studies. The third part describes the research agenda for a large German center grant focusing on mechanisms of emotion dysregulation in BPD.
\end{abstract}

Keywords: Borderline personality disorder, Emotion processing, Social interaction, Neuroimaging, Genetics

\section{Current state of knowledge}

Borderline Personality Disorder (BPD) typically begins during adolescence, shows a peak of symptom severity during young adulthood, and appears to decline modestly but steadily over the years. A large-scale prospective study conducted in the US [1], which is currently viewed as the most valid, showed remission rates of $86 \%$ after a 10-year follow-up (defined as a minimum of 4 years not meeting DSM-IV BPD criteria). These findings have usually been interpreted as indicating that most borderline patients attain a reasonably good overall outcome 10 years after the index admission. However, a more recent analysis of long-term social integration of this population showed that only $50 \%$ of patients achieved both remission from BPD symptoms and good

\footnotetext{
* Correspondence: christian.schmah|@zi-mannheim.de

'Department of Psychosomatic Medicine and Psychotherapy, Central Institute of Mental Health Mannheim, Medical Faculty Mannheim / Heidelberg University, J 5, 68159 Mannheim, Germany

Full list of author information is available at the end of the article
}

social and vocational functioning for a minimum of 2 years [2]. Good social functioning was defined as having a score of at least 61 on the Global Assessment of Functioning (GAF) scale. Of those who achieved recovery, 34\% later relapsed, resulting in a 10 years total recovery rate of about $35 \%$.

These long-term data are based on samples assessed in the US starting in the 1990s, a time when development of disorder-specific treatments was in its infancy. It might be argued that the relatively low recovery rates are due to a lack in specific psychiatric care management. Within the last decade, a number of specific psychosocial treatments with evidence of both effectiveness and efficacy have been developed (for overview, see [3]), and most of these treatments show medium to large effect sizes in the reduction of typical borderline behavior or psychopathology. However, social integration of BPD patients continues to be problematic: up to $50 \%$ of treated patients have a GAF score lower than 60 , indicating persistent serious social problems that may correspond to the 
long-term follow-up data cited above. One possible interpretation of these data is that social integration of patients with BPD (and thus recovery) is impaired by factors distinct from those targeted by the currently existing best practice treatments. If so, this necessitates further research into the underlying pathophysiology, which we propose below may be linked to emotional dysregulation, and the transfer of those findings into a new generation of psychotherapeutic interventions. We will describe central mechanisms of BPD in the following; it should be noted that these do not necessarily correspond to the Research Domain Criteria suggested by the NIH.

\section{Phenomenology of emotion processing in BPD}

A confirmatory factor analytic study of BPD [4] revealed three core domains of psychopathology: affective dysregulation, interpersonal disturbances, and behavioral dysregulation. Three recent large twin studies have all pointed to a common pathway model with one highly heritable general BPD factor [5-7]. The last two of these revealed two additional common liability factors, mainly reflecting affective and interpersonal dimensions. Currently, there is an ongoing debate about the hierarchy of these domains and their potential interactions [8]. From a sociobiological point of view, most of the interpersonal problems of BPD patients (such as rejection sensitivity, difficulties in cooperation, and hostile behavior) can be seen as being driven by dysfunctional emotion processing. From a developmental point of view, aversive interpersonal experiences (such as insecure primary care, early loss, or sexual abuse) can be seen as leading to dysfunctional social cognitions that induce problems in emotion regulation. However, rather than discussing these interactions as a chicken-and-egg problem, one can see them as circular mechanisms. According to an established model by Gross [9], emotion regulation in general includes not only social assumptions and neural regulatory mechanisms but also implicit action tendencies and social interaction.

Experienced clinicians have long suggested affective dysregulation as a core feature of BPD and a driving force behind several serious dysfunctional behavioral patterns [10-14]. Affective dysregulation is related to the frequency with which patients use maladaptive strategies to regulate affect [15] and predicts other BPD behaviors [14], including suicidal ideation and suicide attempts $[16,17]$, maladaptive interpersonal behaviors, and impulsive coping behaviors [18] such as alcohol abuse [19].

Several recent empirical studies have confirmed these clinically based observations. It has been demonstrated that, under both daily life and experimental conditions, BPD patients experience significantly more intense aversive emotions, higher tension, and more volatility of mood than do healthy controls [20-23]. In particular, ambulatory assessment (AA), the favored assessment methodology for acquiring data under natural conditions, has provided insight into the phenomenology of affective instability that is present in BPD. Several studies based on AA have yielded consistent findings, revealing an overall heightened affective instability of patients with BPD compared with healthy controls (for an overview, see [24]). It should be stated that these patterns of affective instability do not seem to be specific for BPD. As Santangelo and coworkers [25] recently showed, similar patterns have been found in samples of patients with posttraumatic stress disorder (PTSD) or with binge eating disorder.

When it comes to distinct and specific emotions in BPD, social emotions such as shame, guilt, disgust, and the fear of social rejection seem to be the most important [26-30] (Domsalla M, Liebke L, Thome J, Haeussler K, Bohus M, Lis S: Rejection Sensitivity and Symptom Severity in Patients with Borderline Personality Disorder: Effects of Childhood Maltreatment and Self-Esteem. In Borderline Personality Disorder and Emotion Dysregulation.; 2014. submitted). According to both clinical and scientific perspectives, the experience of high levels of aversive tension often engenders marked dissociative symptoms, which in turn are related to hypoalgesia [31,32]. Emotional learning may be largely inhibited during dissociative states [33]. Dysfunctional emotion regulation may lead to strong aversive tension in line with dissociative experience, which in turn hinders adequate emotional learning. There is strong evidence that non-suicidal self-injury (NSSI), a phenomenon very often observed in BPD, is mostly used to down-regulate these states of aversive tension or to stop dissociative states [34-36].

Before we discuss the distinct mechanisms of dysfunctional emotion processing in BPD, a short overview is given on the current taxonomy of emotion processing in general.

\section{Basics of emotion processing}

From a socio-psychological perspective, emotions may be thought of as complex and evolved patterns of response to both external and internal stimuli, providing a fast situational interpretation along with a corresponding action tendency. Emotion processing involves automatic and intentional processes that influence the occurrence, intensity, duration, and expression of emotions. There is a wide spectrum of theories on how emotions can influence self-theory, identity, decision-making, social interaction, and even policy (for overview, see [37]).

Among others, Gross and colleagues [9,38] have proposed a model of emotion regulation, based on influential emotion theorists (e.g., [39-41]), which emphasizes the explicit or implicit appraisal of external or internal emotional cues that trigger a set of experiential, 
physiological, and behavioral response tendencies. This model has already influenced treatment development for BPD [42] and might serve as a current basis for research. According to this model, emotions can be modulated automatically or by either manipulating the input to the system (antecedent-focused emotion regulation strategies) or by manipulating the output of the regulation process (response-focused emotion regulation strategies). Antecedentfocused strategies include both implicit and explicit strategies, such as situation selection or modification and cognitive techniques (e.g., reappraisal, attention deployment, or reframing of the situation), while response-focused strategies include both implicit and explicit strategies that can be subdivided into physiological, cognitive, and behavioral processes.

However, Gross's model does not consider the potential role of emotional awareness or experiential avoidance in emotion regulation. One could argue that emotion regulation is mostly an automatic process, independently of cognitive meta-awareness. On the other hand, recent research has clearly demonstrated the potential role of experiential avoidance in the pathogenesis of psychic disorders. Experiential avoidance (EA) not only includes any behavior that seeks to avoid, or escape from, unwanted internal experiences or those external conditions that elicit them, but also the pure awareness of activated emotions [43]. Consequently, increasing emotional awareness and emotion acceptance is currently seen as an important mode of action in psychotherapy in general and in BPD [44]. Schramm and coworkers [45] showed that borderline personality features were associated with significantly higher levels of EA and difficulties in emotion regulation. Hierarchical regression analyses showed that EA made a small but significant incremental and independent contribution to borderline features when added to a model that already included difficulties in emotion regulation.

On a neuroanatomical level, the central areas involved in the "emotion regulation circuitry" are thought to be the dorsolateral and ventral areas of the prefrontal cortex (including the anterior cingulate cortex $[\mathrm{ACC}]$ ), as well as the amygdala, the hippocampus, and the insula [38]. It should, however, be stressed that these regions fulfil several functions besides emotion regulation as well. Ochsner and Gross suggested a psychobiological circular model of emotion processing whereby emotions are generated and modulated by interplaying macro- and micro-circuits of "bottom-up" and "top-down" processes. According to this model, central areas such as the amygdala and the insula are involved in the evaluation of external and internal stimuli regarding their emotional valence. These stimuli are further processed in the hypothalamus and in brain stem regions in order to activate autonomic and behavioral responses. In parallel, prefrontal and parietal cortical areas serve to allocate attention and to activate potential behavioral responses. Regulatory processes associated with areas of the lateral and medial prefrontal cortex (MPFC) act to control and modulate emotional activation, thereby covering typical response-focused regulation strategies. Recent studies suggest a regulatory hierarchy, whereby the dorsolateral prefrontal cortex (DLPFC) and areas of the anterior medio-prefrontal cortex modulate the cingulate, which in turn modulates the amygdala and further subcortical areas $[46,47]$.

Importantly, these regulatory interactions are sensitive to genetic variation in candidate genes that have been reported to have an impact on personality as well as on the risk for affective disorders and for which geneenvironment interactions with early childhood trauma have been found [48-50]. Recent work has extended these results to genome-wide significant risk variants for severe psychiatric disorder [51] and has suggested a common circuitry for emotion regulation and extinction on which genetic and environmental risk factors converge [52]. Regulatory processes can also be activated by cognitive reappraisal, by changing attention, or by activating memories [50]. These cognitive strategies result in an activation of lateral and medial prefrontal areas which, in turn, involve the ACC and ultimately dampen emotional arousal by attenuating the activity of the amygdala, the mid-cingulate, and areas of the insula (for review, see [50]). It should be stressed here that mechanisms of emotion regulation are subject to genetic variation, to maturing processes, and to inter-individual variation, as well as to environmental risk factors such as early adversity or poverty. Notably, during adolescence, there appears to be a marked imbalance between increased sensitivity and susceptibility of subcortical limbic areas to emotional stimuli and not yet fully mature prefrontal areas. This imbalance may account for the tendency towards high emotional activation and impulsivity during adolescence in general (reviewed in [53-55]).

\section{Pathophysiology of emotion processing in BPD}

This section will give an overview about findings in the fields of genetics, structural imaging and spectroscopy, functional imaging, pain processing and dissociation, as well as neurochemistry.

\section{Genetics of BPD}

To date, the only studies on the genetics of BPD have been small-scale and have yielded mostly inconsistent results. A recent meta-analysis [56] found no direct role of more than 20 investigated genetic variants in BPD or BPD traits. No associations between BPD traits and three serotonergic polymorphisms, two common polymorphisms of the serotonin transporter gene (SCL6A4), 
the promotor insertion/deletion (5-HTTLPR) and the intron 2 VNTR, or the rs 1800532 polymorphism of the tryptophan hydroxylase 1 gene (TPH1) were found. All studies, however, were conducted with very small sample sizes, and to date there has been no published genomewide association study in BPD. On the other hand, a genome-wide analysis and replication study of borderline personality features [57] has been conducted in three Dutch cohorts, which were comprised of a total of 8426 participants. While no genome-wide significant association was identified, the top findings which could be replicated in the independent replication sample were located in a region corresponding to SERINC5, a protein involved in myelination.

More promising avenues of study might use gene $\mathrm{x}$ gene (e.g., $[58,59]$ and gene $\mathrm{x}$ environment approaches (e.g., [60] interactions). Interestingly, Distel and coworkers [61] were able to demonstrate that the impact of genetic factors on BPD features is lower in individuals who have been victims of sexual abuse than in those who have experienced other serious life events. Epigenetic research in BPD is also just beginning [62]. A pilot study on mRNA gene expression demonstrated no effect of BPD per se, but an effect of dissociation on the expression of genes involved in immune system regulation as well as cellular signalling/second-messenger systems [63].

\section{Brain structure}

("In this paragraph, the following annotations for replication were included: $A=$ replicated by more than one research group, $B=$ replicated by members within the same research group, $C=$ single study only without replication).

Among the most robust findings of structural imaging in BPD patients are reduced volumes of the amygdala, the hippocampus, the OFC, and the ACC $[64,65]\left(\mathrm{A}^{*}\right)$. The most recent meta-analysis, which incorporated 11 studies with 205 BPD patients and 222 healthy controls, showed an average decrease of $11 \%$ in the size of the hippocampus and of $13 \%$ in the size of the amygdala [66]. Another meta-analysis demonstrated that hippocampal reductions are more pronounced in BPD patients who have comorbid PTSD. In those without PTSD, right but not left hippocampal volumes were reduced [67]. More recently, a whole-brain voxel-based morphometry (VBM) study in 60 patients with BPD confirmed volume reduction in the hippocampus and amygdala as well as in the fusiform and cingulate gyri [68]. A further study [69], which enrolled 30 BPD patients and 33 controls, found the gray matter of patients with BPD to be reduced in the hippocampus but increased in the hypothalamus compared to healthy participants. Hypothalamic volume correlated positively with the history of traumatization in BPD patients [70] $\left(\mathrm{C}^{*}\right)$. Another VBM study demonstrated that BPD and bipolar disorder have relatively distinct patterns of structural alterations, with mostly fronto-limbic alterations in BPD [71] $\left(\mathrm{C}^{*}\right)$, however these data need replication within a larger sample. Reduced volumes of the left ACC and the right OFC (but not of the amygdala or hippocampus) were detectable in a first study including adolescent BPD patients (average age 17.4 years), and were found to correlate with impulsivity and non-suicidal self-injury [72,73] $\left(C^{*}\right)$. Specific differences were also found between criminal offenders with either BPD or psychopathy [74] $\left(\mathrm{C}^{*}\right)$. The BPD offenders had lower volumes in the orbitofrontal and ventromedial prefrontal cortex regions subserving emotion regulation and reactive aggression, while, for psychopathic offenders, the most significant volumetric reductions were in the midline cortical areas involved in the processing of self-referential information and self-reflection.

Ruesch and coworkers [75] $\left(\mathrm{C}^{*}\right)$ used diffusion tensor imaging (DTI) to investigate the relationship between white matter integrity in the inferior frontal cortex and several core symptoms of BPD, as well as to measure the neuropsychological performance of BPD patients with co-occurring attention-deficit-hyperactivity disorder (ADHD). Initial evidence was found for a possible relationship between core symptoms of BPD and structural alterations of the white matter in the inferior frontal cortex, as the average diffusion in the inferior frontal cortex was related to affective dysregulation, anger/hostility, and dissociation. However, no significant group differences were detected in the DTI measurements between BPD patients and healthy controls. Additional analyses of this sample revealed abnormalities of inter-hemispheric connectivity between both sides of the anterior cingulate [76] $\left(\mathrm{C}^{*}\right)$. Further DTI studies showed decreased fractional anisotropy (FA) in the genu and rostral areas of the corpus callosum as well as in left and right prefrontal white matter [77] $\left(C^{*}\right)$ in BPD adults and in the fornix in BPD adolescents [78] $\left(\mathrm{C}^{*}\right)$. New and coworkers [79] $\left(\mathrm{C}^{*}\right)$ found decreased FA in the inferior longitudinal fasciculus and other areas in BPD adolescents but not in BPD adults. This most probably speaks for a transient disturbance of connectivity in the development of BPD.

According to two MR spectroscopy study, the absolute concentration of $\mathrm{N}$-acetyl aspartate (NAA) in the DLPFC is reduced by $19 \%$ in BPD patients, suggesting a reduced cell density or a functional impairment within this region [80] $\left(C^{*}\right)$. Compared with healthy controls, subjects with BPD were found to have reduced NAA concentrations in the amygdala [81] $\left(\mathrm{C}^{*}\right)$ and significantly higher levels of glutamate in the ACC [82] ( $\left.\mathrm{B}^{*}\right)$. In the latter study, which could recently be confirmed in a new sample (Ende, Cackowski, van Eijk, Sack, Sobanski, Krause-Utz, Schmahl: Impulsivity and aggression are differentially 
associated with anterior cingulate glutamat and GABA concentrations in Borderline Personality Disorder and Attention-Deficit-Hyperactivity Disorders. In preparation), a positive correlation between glutamate concentration and self-rated impulsivity was observed, as well as between glutamate concentration and dissociation scores.

\section{Neurochemistry}

Initial studies on the neurochemistry of BPD primarily focused on the hypothalamic-pituitary-adrenal (HPA) axis as well as on the serotonergic, glutamate, oxytocin, and opioid systems.

\section{HPA axis}

Findings with respect to the HPA axis are inconsistent, possibly due to confounding effects of co-occurring disorders such as depression and PTSD and small sample sizes. While one study reported increased salivary cortisol levels under daily life conditions [83], another found a significantly reduced cortisol response to experimentally induced social stress [84]. Notably, in this study, the reduced cortisol response was not paralleled by reduced ACTH secretion, which might suggest a stress-associated hypo-activity of the adrenal cortex. A similar hypo-activity in response to the Trier Social Stress Test (TSST) was found in adolescents with NSSI, nearly half of whom fulfilled diagnostic criteria for BPD [85]. In contrast to healthy controls, cortisol administration enhanced rather than impaired memory retrieval in BPD patients [86], which is similar to the effects it has on PTSD patients [87].

\section{Serotonin}

This neurotransmitter system has important regulatory functions in frontro-striatal circuits, and dysfunctions which are considered to be important predictors for impulsive behavior $[88,89]$. Subjects with impulsive and aggressive behavioral tendencies were consistently found to have reduced cerebrospinal fluid (CSF) concentration of the metabolite 5-HIAA and reduced neuroendocrinological reaction to serotonergic agonists (e.g., D- or D,L-fenfluramine, meta-chlorophenylpiperazine) [90,91]. Neuroimaging studies, each conducted in only 8 BPD patients (e.g., [92,93]), have revealed altered metabolism at baseline as well as in response to serotonergic challenge in prefrontal regions including the ACC. SSRI treatment (fluoxetine $20 \mathrm{mg} /$ day) normalized prefrontal cortex dysfunction in impulsive-aggressive BPD patients in one study. [94].

\section{Oxytocin}

As a key mediator of trust behavior, the neuropeptide oxytocin (OT) is involved in attachment and pro-social behavior [95]. Furthermore, it has been shown that OT modulates stress responses, especially in social contexts, and may be affected by early life adversity [96]. Parents reporting greater parental care showed higher plasma OT, low-risk CD38 alleles, and more physical contact with their infants [97]. On a neurobiological level, there is rising evidence that the application of OT might attenuate the response of the amygdala to emotional stimuli [98]. The specific circuit on which OT has an impact is a convergence zone for genetic and environmental risk [52]. Thus from a developmental as well as a neurobiological point of view, it appears plausible that alterations of the OT system might be involved in the pathophysiology of BPD [99]. Correspondingly, Bertsch and coworkers [100] reported decreased peripheral OT concentrations in female BPD patients, which negatively correlated with severity of early traumata. Interestingly, a pilot study [101] found that intra-nasal application of OT impaired trustful expectations in BPD subjects, showing that while the OT system seems to be disturbed in BPD, a simple substitution of the neuropeptide may not fix the problem. Bertsch and coworkers [102] found a normalization of abnormal behavioral and neuronal patterns after intranasal OT application while BPD patients were scanning angry faces, suggesting that OT may decrease threat hypersensitivity in this group of patients.

\section{Opioids}

Attenuated pain perception and the lack of effective emotion regulation in BPD implicate a potential dysfunction of the endogenous opioid system [99,103]. BPD patients with NSSI behavior were found to have significantly lower levels of CSF $\beta$-endorphin and metenkephalin when compared with a non-NSSI BPD group [104]. A PET study [105] found that under neutral conditions, BPD patients compared to controls showed greater regional $\mu$-opioid receptor availability bilaterally in the orbitofrontal cortex, caudate, nucleus accumbens, and left amygdala but lower $\mu$-opioid receptor availability in the posterior thalamus; whereas during emotion induction (sadness), they showed greater activation of the endogenous opioid system in the pregenual anterior cingulate, left orbitofrontal cortex, left ventral pallidum, left amygdala, and left inferior temporal cortex.

\section{Brain function and networks}

("In this paragraph, the following annotations for replication were included: $A$ = replicated by more than one research group, $B=$ replicated by members within the same research group, $C=$ single study only without replication).

The cerebral processing of emotional stimuli in BPD patients has been investigated in several PET and fMRI studies. One study [106] found bilateral amygdala hyperactivity in BPD patients while viewing emotionally aversive pictures. This finding has been repeatedly replicated with elevated amygdala responses to neutral pictures as well [107-110] $\left(A^{*}\right)$. A recent finding of decreased 
amygdala habituation in response to repeatedly presented stimuli is consistent with the clinical observation of abnormally strong and long-lasting reactions to emotional cues $[111]\left(C^{*}\right)$. Functional imaging studies using cues or scripts to induce BPD-specific characteristics are indicative of disturbed functioning in prefrontal regions. For instance, script-driven induction of traumatic events or of social separation in traumatized female BPD patients and traumatized women not meeting BPD criteria resulted in a lower activation of both the ACC and the OFC in the former $[112,113]\left(B^{*}\right)$. Studies on functional correlates of response inhibition have yielded further evidence for functional impairments of prefrontal areas, notably of the DLPFC, the rostral ACC, and the OFC [114] $\left(C^{*}\right)$. Minzenberg and coworkers [115], using an implicit affect regulation task (responses to threatening vs. neutral faces), demonstrated specifically enhanced neural activation of the right amygdala in BPD along with attenuated activations of the rostral ACC. In response to an explicit affect regulation task based on reappraisal strategies, OFC hypoactivation, in addition to insular hyperactivation, was found, while negative emotions were down-regulated [109] $\left(\mathrm{C}^{*}\right)$. In a study that used attentional distraction as a further regulation task, BPD patients were shown to exhibit higher left-sided amygdala activation than healthy controls [116] (C*). Reduced connectivity between the OFC and the amygdala in BPD patients was reported by New and coworkers [117] $\left(C^{*}\right)$. Interestingly, in a pilot study, successful psychotherapy was found to be paralleled by normalization in the amygdala response as well as in prefrontal top-down areas [118] $\left(\mathrm{B}^{*}\right)$. These findings were recently corroborated in a larger controlled trial (Schmitt, Niedtfeld, Winter, Herpertz, Schmahl unpublished observations). A recent meta-analysis of fMRI studies across different stimulation methods revealed greater activity in the insula and reduced activation in the subgenual ACC and DLPFC in BPD patients as compared to controls [119] $\left(\mathrm{A}^{*}\right)$.

\section{Pain processing and dissociation}

As already mentioned, reduced sensitivity to pain (hypoalgesia) and a close relationship between stress and hypoalgesia have been consistently reported in BPD patients [120-124]. The sensory-discriminative component in pain processing does not appear to be disturbed, but abnormalities have been detected for affective pain processing. More specifically, a deactivation of the amygdala has been found during pain induction in BPD patients $[122,125]$. A modulation of the affective pain component in BPD patients by the well-known COMT val158met polymorphism has been demonstrated [126], however this findings needs replication. Furthermore, higher BPD symptom severity and trait dissociation were associated with an attenuated signal decrease of the default mode network in response to painful stimulation, and patients with BPD exhibited less posterior cingulate cortex connectivity with the left DLPFC during painful stimulation [127]. Preliminary evidence from recent studies indicates specificity of reduced pain sensitivity, as no differences in proprioception and exteroceptive sensitivity were found $[123,128]$. Also, no differences between BPD patients and controls were found regarding interoception in a task where participants had to observe and count their own heartbeats [129].

In a study that tested the aspect of emotion regulation by sensory stimulation, pain that was experimentally induced by thermal stimuli was found to result in the attenuation of amygdala hyperactivity induced by affective pictures [108]. Functional connectivity analyses revealed normal inhibitory connectivity between the left amygdala and MPFC and between the right anterior insula and DLPFC when negative pictures were combined with painfully hot stimulation but not when they were combined with non-painfully warm stimulation [130], suggesting that there may be a specificity of painful stimuli in the context of sensory emotion regulation in BPD. Using incision-induced pain, which takes into account tissue damage and thus provides a more valid model for non-suicidal self-injury, a stress-reducing effect of an incision in the forearm in terms of reduced subjective arousal and increased heart rate variability could be demonstrated [131]. These findings were recently replicated in an fMRI study in which an additional restitution of post-stress amygdala-mPFC coupling following incision was shown (Reitz, Kluetsch, Niedtfeld, Knorz, Lis, Paret, Kirsch, Meyer-Lindenberg, Treede, Baumgaertner, Bohus, Schmahl: Incision and stress regulation in borderline personality disorder. neurobiological mechanisms of self-injurious behavior. Submitted).

It has been suggested that dissociation constitutes an emotional over-modulation mode that responds to the experience of (traumatic) stress, as opposed to an emotional under-modulation mode with predominantly intrusive symptoms and that these two modes can be segregated on a neurofunctional level [132]. In particular, over-activity of medial prefrontal brain regions with concomitant limbic down-regulation is hypothesized to underlie dissociative psychopathology. Corroboration of these assumptions comes from several sources. In one study, patients with high levels of dissociation were found to have significantly lower startle responses compared to those with low levels of dissociation [133], while another study found that dissociation scores were negatively correlated with activity in the amygdala, insula, and ACC during emotional distraction that took place while the participants were performing a working memory task [134]. Dissociative phenomena have some similarity with 
body-related illusions such as out of body experiences and it might therefore be useful to expand the research on these phenomena from nociception and pain processing to the processing of body perception, which has been shown to be altered in BPD [135] .

\section{Interpersonal disturbances}

Interpersonal disturbances have been central to characterizations of BPD since the earliest descriptions of this disorder [136]. In the last few years, clinically based observations have been confirmed by empirical data that support alterations of the social lives in BPD. Romantic partnerships are characterized by high instability in the form of frequent breakups and reconciliations accompanied by low marital satisfaction, high attachment insecurity, communication problems, a high level of physical and psychological violence, and a tendency to choose partners who also have mental problems [137-139]. Several studies observed altered maternal behavior linked with impaired social interaction behavior in the children of BPD patients [140-142]. However, one should be careful about generalizing these premature findings, which are based on small and selective samples. In everyday life, BPD patients often experience more unstable social relations than healthy controls as well as fewer social interactions and have sometimes been shown to use maladaptive resources for social support within their social network $[143,144]$.

\section{Social interaction in $B P D$}

Social interaction problems have been investigated in BPD using questionnaires and experimental approaches that aim to measure behavior directly during natural or standardized interaction situations [145]. Subjective assessments in questionnaires point to BPD patients showing highly variable and more extreme interaction behaviors, which have been described as more hostile, more quarrelsome, and less affiliative in nature $[143,146]$. However, it must be noted that findings based on self-based or observer-based ratings primarily reflect the perception of a subject's competence, which might differ from their actual behavior during a social encounter.

In the last several years, an increasing number of studies have applied experimental approaches that measure interaction behavior in standardized situations within distinct social domains. Specifically, they have investigated dyadic or triadic interactions in the context of social exclusion, provocation of aggressive behavior, and the ability to display trustful and cooperative behavior (for review, see [145]).

\section{Social rejection during social encounters}

Several studies have used a virtual ball-tossing game called "cyberball" [147] to induce the experience of social rejection, which, together with intense fear of loss and abandonment, may constitute a central factor of interpersonal relationships in BPD. In this game, the coplayers' behavior is manipulated to mimic inclusion, exclusion, or neutral control conditions, during which the players act according to predefined rules; i.e., without personal motivations. In recently published studies, BPD patients were found to feel more excluded during the inclusion and neutral conditions [148-151]. The experience of social exclusion evoked especially intense negative emotions such as contempt, resentment, and anger, which were focused on others [150]. These findings suggest that the awareness of social exclusion and the resulting emotional reactions in BPD patients differ from those of healthy individuals. It is worth emphasizing that this seems to be true not only during the experience of social rejection but also during the inclusion and neutral situations. A recent fMRI-study linked these alterations to a lack in the modulation of activation in brain regions such as the insula and the precuneus depending on the nature of the social encounter [151].

No studies have yet addressed how BPD patients cope with the experience of social rejection, such as whether they tend to punish excluders or engage in self-protective strategies, as healthy individuals have been shown to do $[152,153]$. Such studies may provide insight into the mechanism of dysfunctional social interaction behavior and may constitute the basis for the development of specific therapeutic intervention strategies.

\section{Social-cognitive information processing}

Social interaction behavior is based on a multitude of social cognitive processes, including the ability to recognize emotions or intentions in social partners. An increasing number of studies have confirmed that these processes are affected in BPD, although the exact nature of these alterations is still under debate. Studies on the decoding of facial expressions suggest that BPD patients show a heightened sensitivity to negative emotional cues [154-157]. However, other studies have shown impairments in detecting and labeling emotions for both negative and positive valent emotional expressions [158-162]. These heterogeneous findings point to the need to investigate which factors, such as social and non-social stress, emotion regulation abilities, dissociative symptoms, and the necessity of coordinating these functions with others in order to guide social interactions, modulate emotion recognition in BPD [163]. Empirical findings point to a social cognitive bias [164]. For example, Staebler and coworkers found that experimentally induced social rejection led to a negative bias for perceived social participation [165], while Barnow and coworkers [146] found that BPD patients have an interpretational bias which leads them to assume that 
others are hostile and angry. Similarly, Domes and coworkers [166] found a bias for recognizing angry facial expressions in ambiguous faces, a finding that was recently replicated in a larger sample (Izurieta, Bertsch, Herpertz unpublished). These data fit with studies that investigated trust and cooperation in exchange games established in behavioral economy. On a behavioral level, King-Casas and coworkers [167] used a multiround trust game to demonstrate that BPD patients showed less generous behavior than healthy controls, leading to a breakdown in cooperation over the course of the interaction. Similarly, Unoka and colleagues [168] found that BPD patients failed to develop trust in an interaction partner during a multi-round trust game when they did not receive feedback about their partner's behavior. These experimental data fit with the concept of BPD as a disorder of "mentalization", which gave rise to the development of "Mentalization Based Therapy" - a BPD-specific psychosocial treatment which has proven to be effective $[169,170]$.

The term "mentalization" is derived from theory of mind, and concerns a complex cognitive and affective understanding of self and others and enables individuals to navigate effectively in the social world. However, while the concept of mentalization is a useful heuristic approach, it has been criticized as being too broad and multifaceted to be operationalized as a marker for specific BPD pathology [171]. An increasing number of experimental studies aim to precisely measure different components of mentalizing and its behavioral and cerebral alterations in BPD [163,172-176]. In the future, these findings may allow identification of the components of mentalizing that are altered in BPD and, as a consequence, lead to further refinement of theoretical concepts and corresponding therapeutic interventions.

\section{Animal models}

Animal models of neuropsychiatric disorders are a valuable tool and an indispensable part of neurobiological and psychiatric research that might even have direct relevance as biomarkers for clinical conditions. It is often very difficult to determine causal relationships between a given symptom and pathological alterations or contributing factors in clinical studies, but animal models enable the examination of direct causal relationships between behavioral and neurobiological abnormalities. The detailed neuropathology and the etiology of BPD are very complex and are only partially understood; hence, valid animal models for BPD are urgently needed and might offer crucial insights into the understanding of basic neurobiological processes. However, the development of suitable animal models of psychiatric disorders poses major challenges $[177,178]$. Generating a valid and potentially holistic animal model requires profound knowledge of the etiology, pathogenesis, and pathophysiology of a given disorder, and this detailed knowledge is not available for many neuropsychiatric conditions. Multiple and varied causal factors may induce similar phenotypes [177], raising further complications.

The difficulties in establishing valid animal models in neuropsychiatric research become particularly apparent in the study of personality disorders, which are associated with ways of thinking and feeling about the self and others that significantly and adversely affect how an individual functions in many aspects of life. Many of these features are uniquely human and can only be inferred with strong limitations in rodent models. Of the core behavioral traits of BPD, only some sub-aspects, such as emotional reactivity toward aversive/appetitive events, impulsive behavior, pain processing, social competence, and social needs (e.g., social recognition, social trust, and the incentive value of social contact), can be assessed with adequate face validity in rodents (e.g. [179-181]). In particular, an aberrant social endophenotype can be modeled and examined with high validity in laboratory rodents (especially in rats) since rats and mice are highly social, have complex social structures, and express a rich repertoire of behavior patterns used for social recognition, affiliation, sex, and aggression [179,182].

Recently, a novel rat model was established for social rejection in order to assess the acute and long-term consequences of such adverse peer-experiences in adolescence at both the behavioral and the molecular level [183]. Since BPD patients often show an augmented sensitivity toward social rejection [184], this model is also of relevance for BPD research. The model is based on specific social requirements of adolescent rats, which spend more time interacting with peers than do younger or older animals. These peer-directed activities (mostly social play) have a considerable incentive value [185] and are crucial for the development of social competence [186]. In order to model social rejection, adolescent rats of the playful Wistar strain were paired with either a same-strain partner or a less playful Fischer344 strain rat, which is an inadequate social partner for a Wistar rat. Pairing with such an inadequate social partner throughout adolescence was found to decrease later adequate playful peer-interactions for Wistar rats without depriving the animals of normal social contact. In the long-term, these manipulations were found to increase the pain threshold and emotional reactivity in these animals and to concomitantly induce alterations in corticosterone release and aberrations in the endocannabinoid system in the amygdala and the thalamus [183].

\section{Conclusions}

Clinical, phenomenological, and experimental findings are evidence that emotion dysregulation and maladaptive 
interpersonal behavior are core features of BPD. Disturbances of emotion processing typically translate into dysfunctional expectations and interpretations in the context of social interactions, and vice versa. On a neuroregulatory level, this could be manifested through disturbances of the hierarchically modulated prefrontal and prefrontal-amygdalar control circuits. Consequences of these dysregulations include intense aversive tension (which often leads to reduced executive functioning), temporary disruption of integrative psychic functions (dissociation), and the activation of learned maladaptive coping strategies. From an interpersonal perspective, the most robust findings are dysfunctional interpretation of social cues, hyper-mentalization, problems with coaxing, and hypersensitivity to social rejection and threat. Each of these dysfunctional social cognitions is closely linked to the emotional system, resulting in intermittent experiences of intense fear of abandonment, social rejection, and a strong desire for unconditional love.

\section{Where do we go from here?}

As shown above, the model of close interaction between emotion dysregulation and disturbed social cognition in BPD has been corroborated by a multitude of experimental findings during the last decade. However, important questions still remain. First, we should clarify which of these findings can be identified as prototypical BPD-specific alterations and which can be better characterized as secondary "scars" of life-long chronic stress, medication, or substance abuse. Consequently, we should widen our scope beyond the limits of acute psychopathology. Within this context, we should clarify which of the disturbances observed in adult BPD patients can be traced back to adolescence. Subtle neurobiological alterations might be detectable already in childhood and reveal themselves more strongly in adolescence and early adulthood. Second, as most of the previously published studies did not include clinical controls, we need to establish to what extent psychobiological alterations are specific to BPD. Third, the vast majority of studies has been conducted in female BPD patients, although field trials suggest that males may be equally affected. Fourth, current evidence does not allow for a conclusive interpretation of differential disturbances of neural sub-components involved in emotion processing and social interaction. Finally, the promising attempts to establish animal model for BPD pathology should be continued. In the following sections, we delineate some shortcomings in particular domains of research.

\section{Pathogenesis and life course}

While the pathogenesis of BPD is not yet fully understood, most researchers favor a model that postulates an interplay between genetic predisposition and psychosocial stress during childhood and adolescence. Several studies support that sexual, physical, and emotional traumata manifesting themselves through intense social rejection sensitivity play an important role in the development of BPD [187,188]. It is unclear whether and how these experiences translate into alterations of neural systems on a neurochemical, functional, and morphological level and ultimately result in disturbed emotion processing or to what extent certain neurobiological characteristics are vulnerability factors for this course and predate the problems in emotional processing. This question could be causally addressed with an adequate animal model. Although some small-scale association studies have been conducted, there is a lack of conclusive data on the potential role of genetics in the development of BPD. This is partly due to the complex interplay of different mechanisms. In particular, progress in genetic research is hampered by a lack of well-defined endophenotypes, i.e., traits with a neurobiological substrate that persist after remission from acute psychopathology [189].

Another field that still contains many unanswered questions pertains to the course of BPD. Evidence from longitudinal studies points to a rapid reduction of the number of fulfilled BPD criteria per individual within a few years, with remission rates of up to $99 \%$ at 16 -year follow-up [6,190]. However, this might be misleading since longitudinal studies have also demonstrated that levels of psychosocial impairment do not significantly decline, and that "temperamental" symptoms of BPD such as dependency and anger are more persistent over time [190], even after formal remission according to diagnostic criteria has been reached. A cross-sectional comparison of younger (18-25 years) and older ( $>45$ years) BPD patients showed that, although the prevalence of individual symptoms such as impulsivity, suicidal behavior, and affective instability is lower in older patients, the two age groups are strikingly similar in terms of the average number of fulfilled criteria, Axis I co-morbidities, and functional impairment [192].

\section{Emotion processing and neuroimaging}

As described above, several small-scale studies have tested the reactivity of BPD patients to different emotional stimuli such as aversive pictures or faces. Also, recent studies have begun to measure emotion regulation by, for example, combining aversive stimuli with reappraisal or sensory stimulation. However, a comprehensive analysis of an emotion (dys)regulation network in $\mathrm{BPD}$ is lacking. Also lacking are studies that compare different types of emotion regulation paradigms within the same individuals, as well as studies that investigate the influence of treatment (e.g., psychotherapy) on measures of emotion regulation. 
At the current stage of research, the interpretation of volumetric and spectroscopic results is difficult for several reasons. Study samples have often been quite small and have contained subjects with various co-morbidities. Methodological differences between the studies need to be considered, including a lack of differentiation of functionally different subregions within the amygdala, the ACC, and the OFC, as well as differences with respect to field intensities and measurement reports (including voxel size). Furthermore, many studies have included patients who were being treated with psychotropic medications, some of which are thought to have a substantial impact on structural alterations. None of the studies conducted so far has been able to find links between volumetric findings and psychopathologically relevant disturbances of emotion regulation.

\section{Social interaction}

Social interaction can be described as a dynamic sequence of actions between individuals during which the behavior of one participant is continuously modulated by the past actions and anticipated future actions of another. Early studies suggested that the objective behavioral and neurobiological description of this interaction behavior allows for a new perspective on interpersonal dysfunctioning in BPD. However, the number of studies that use such an approach is still very small, and it is unknown how their data fit with findings from self-based and observer-based questionnaires that provide information on how interaction behaviors are subjectively perceived. Furthermore, a successful social encounter is based on the integration of a multitude of social cognitive processes, and a dysfunction of any of these may lead to interpersonal disturbances. Although much attention has been focused in the past on the investigation of impairments of single social cognitive processes in $\mathrm{BPD}$, it is still unknown to what extent these described alterations contribute to the dramatic problems in the social lives of these patients. Thus, future studies need to manipulate these processes experimentally in the context of interactions in order to gain further insight into the mechanisms of impaired interpersonal relations and to enable the design of specific therapeutic intervention strategies.

\section{Animal models}

Animal models, such as the Wistar/Fischer rat model for social interaction described above, have the potential to shed further light on the basic neurological circuits and processes involved in rejection experiences during adolescence. Rodent models addressing discrete symptomatic aspects of BPD are quite useful; however, to date, no holistic animal model has acounted for the etiopathology, developmental aspects, pathogenesis, and complex symptomatology of the disorder. Although the detailed etiology of BPD is still only partially understood, a history of early aversities appears to be closely connected to BPD (for review, see $[188,193,194])$. Social experiences throughout the life span may interfere with gene expression, brain development, and behavior, and it has been shown that these influences have a particularly profound effect during early development. In mammals, mother-infant interactions are the primary source of tactile stimulation for the developing offspring. These stimulations influence not only physical growth but also various neurodevelopmental processes [195-198], and laboratory rodents and nonhuman primates have shown that variances in maternal care behavior induce lasting neurobiological changes and affect offspring phenotype (for review, see $[197,198]$ ).

\section{A research agenda for $B P D$ and ED}

In our view, the overarching aim of BPD research over the next ten years should be to elucidate central pathomechanisms of emotion processing and social interaction in BPD parallel on the subjective, behavioral, and neurobiological levels. Ultimately, the clarification of these central pathomechanisms should improve strategies for primary and secondary prevention and help to optimize assessment and treatments on both a psychotherapeutic and a pharmacotherapeutic level. The first step should be for researchers to investigate central pathomechanisms (disturbed emotion processing and its implications on social interaction) with respect to BPD specificity, age dependence, gender dependence, and long-term stability beyond remission of acute BPD symptomatology. The second step should be to seek validation of identified key mechanisms as potential endophenotypes and to use these to tailor specific therapeutic interventions.

One approach could be to focus on core psychobiological mechanisms in the complex psychopathology of $\mathrm{BPD}$, and to investigate disturbed emotion processing in various facets and at different levels. Some of these mechanisms could potentially be used to define endophenotypes, which should be closer to the site of the primary causes (whether genetic or environmental) than to the diagnostic category of BPD [199]. According to one view [200], endophenotypes for mental disorders are, among other criteria, primarily state-independent, i. e., they manifest themselves whether or not the illness is active. This view also suggests that endophenotypes are related to the development of the disorder and do not mimic long-term consequences or secondary manifestations of co-occurring Axis I disorders. Including remitted patients and adolescent patients in research projects could address these issues. 
A major problem in $\mathrm{BPD}$ and emotion regulation research is that most studies have been carried out by relatively small teams, which unavoidably results in mono-methodological approaches. A multidisciplinary cooperation would enable the integration of morphological, functional, endocrinological, and neuropsychological paradigms and measurement methods. We have therefore started a large collaborative research program, recently funded by the German Research Foundation as a center grant, which may serve as an example of how to transfer a research agenda into a multifaceted and translational program. The central aim of this program, titled "Clinical Research Unit (CRU): Mechanisms of Disturbed Emotion Processing in Borderline Personality Disorder", is to break down the emotion processing and interactive problems of BPD on a psychobiological level and to elucidate the underlying mechanisms. The results will be used to fine-tune and expand currently existing psychosocial treatments and to develop innovative pharmacological approaches. The following presents an overview of the CRU and delineates its major aims and methods.

The CRU consists of nine individual projects (see Figure 1). Projects P1 to P5 focus on psychophysiological and neural parameters related to disturbed social interactions and their implications for emotion regulation, as follows:

- $\boldsymbol{P 1}$ investigates behavioral and neurobiological patterns in response to experimentally induced social exclusion in acute adult and adolescent BPD patients and in remitted adult patients. In one sub-project, a virtual reality paradigm is used to induce the experience of group rejection gradually. In a second sub-project, an established rejection paradigm (cyberball) is examined under fMRI conditions.

- P2 comprises two experimental fMRI paradigms and an electrophysiological paradigm, comparing acute adult and adolescent BPD populations and a remitted adult $\mathrm{BPD}$ population to healthy controls and a clinical comparison group of PTSD patients. It investigates behavioral and neural correlates of BPD patients' hypersensitivity to social threats and what the implications of the tendency to respond with approach or avoidance. Another issue concerns the aggressive and auto-aggressive manifestations of anger, a prominent feature in BPD. Additionally, this project is the first to systematically consider gender effects in BPD by including male participants.

- $\boldsymbol{P} 3$ stems from the findings of King-Casas and coworkers [167] that shows BPD patients' substantial deficits in establishing trust with cooperation partners. This topic is being systematically evolved by using the recently developed method of "hyperscanning" with 2 identical audio-visually linked MRI scanners. This methodology allows investigation of dysfunctions in cerebral regions that are related to basic interpersonal interaction and trust and of the ramifications of these dysfunctions on a behavioral level.

- P4 develops an animal model with face validity and construct validity regarding aspects of the etiology and symptomatology of BPD by modulating early social relationships and social interactions in juvenile

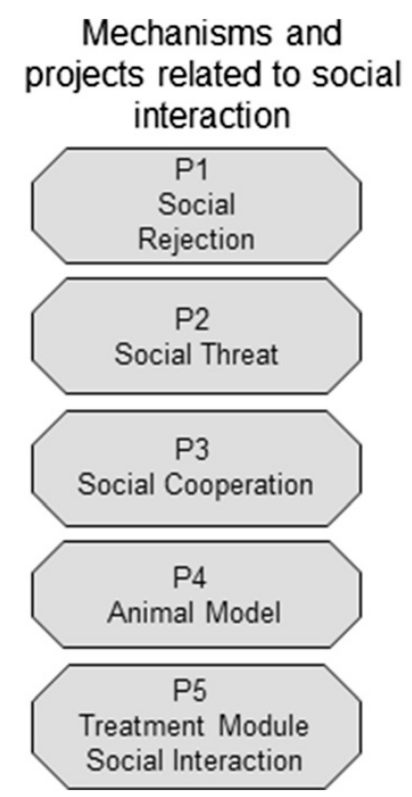

\section{Mechanisms and projects related to emotion processing}

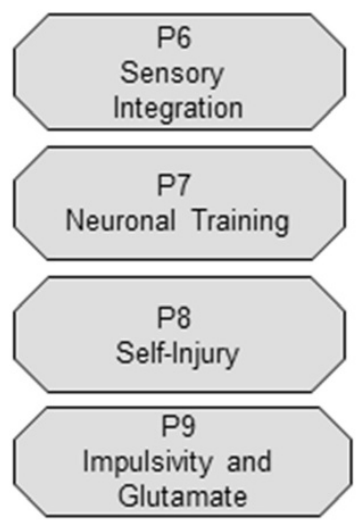

Figure 1 Overview of the mechanisms and projects of the CRU related to social interaction (left) and emotion processing (right). 
and adolescent rats. This is intended to induce core symptoms of BPD such as emotion dysregulation, pain sensitivity, and impulse control. The possible lasting consequences of these manipulations on social, emotional, and motivational behaviors are then assessed at different points in life. In order to achieve face-validity for BPD symptomatology, pain perception and stress reactivity are tested. Furthermore, neurobiological alterations that might underlie behavioral changes (e.g., alterations of the HPA axis, the endogenous opioid system, and the endocannabinoid system) are analyzed in order to strengthen the construct validity and possibly in order to lead to pharmacological intervention strategies. A current research aim is to examine behavioral and molecular consequences of differences in maternal care in the context of BPD in laboratory rats. In a later step, these early modulations of mother-infant interactions will be combined with our adolescent social rejection model in order to study potential additive effects of these two adverse social modulations during different developmental periods.

- P5 develops a treatment module designed to specifically improve the regulation of social emotions and interactions of BPD patients, which will be integrated as a further component of Dialectical Behavior Therapy (DBT). It aims to improve adequate interpretations within the social context, mentalization processes, and the building of trust and cooperation.

Projects P6 to P9 focus on neurobiological parameters of disturbed emotion processing that are primarily located on an intra-psychic (i.e., non-social) level, as follows:

- $P 6$ expands the converging findings on disturbed pain processing and altered body perception in BPD patients, as well as investigating potential disturbances of multisensory interaction. One of its major goals is to discriminate between chronic traits and disturbances resulting from acute stress (dissociation).

- $\quad$ P7 is based of fMRI findings of amygdala hyperreactivity in response to emotional cues in BPD patients. This project expands these findings, and investigates the time course of the blood oxygenation level-dependent (BOLD) response in different brain regions. In a second step, innovative neurofeedback training for BPD using real-time fMRI is established. We assume that it will be beneficial to train patients to control/monitor their neural activity, e.g., by down-regulating limbic hyperactivity.
- $P 8$ investigates an emotion regulation strategy frequently used by BPD patients that involves self-inflicted tissue injury. In one sub-project, the affective components of tissue-damaging and nontissue-damaging pain are investigated. In a second sub-project, following stress induction, incisions will be applied while psychophysiological, neuronal, and neurochemical parameters of emotion regulation are assessed. It is hypothesized that reduction of stress levels will be stronger following tissue-damaging when compared to non-tissue-damaging pain.

- $P 9$ uses spectroscopy to assess glutamate and GABA metabolism in the ACC and also considers the impact of acute stress on executive functions in BPD.

Overall, more than 1000 potential participants are screened, and approximately 300 patients with current or remitted BPD are included in one or more of the abovementioned projects. Patients are screened and allocated to the individual projects via a central core project which also conducts diagnostic assessments. Of course, this research program can only cover some areas that are of relevance in the field of BPD. Besides this program, other aspects of research certainly deserve more attention in the field of BPD, e.g. large longitudinal cohort studies or genome studies. However, with this ambitious research program, we hope to answer several of the open research questions described above and to be able to pave the way for tailoring individualized treatments for patients with BPD.

\section{Competing interests}

The authors declare that they have no competing interests.

Author's contribution

$\mathrm{CS}, \mathrm{SCH}, \mathrm{SL}$ and MB drafted the manuscript. All authors read and approved the final manuscript.

\section{Acknowledgements}

The authors would like to thank the German Research Foundation (DFG) for funding.

\section{Author details}

'Department of Psychosomatic Medicine and Psychotherapy, Central Institute of Mental Health Mannheim, Medical Faculty Mannheim / Heidelberg University, J 5, 68159 Mannheim, Germany. ${ }^{2}$ Department of General Psychiatry, Center of Psychosocial Medicine, Medical Faculty Heidelberg / Heidelberg University, Heidelberg, Germany. ${ }^{3}$ Department of Neuroimaging, Central Institute of Mental Health Mannheim, Medical Faculty Mannheim / Heidelberg University, Mannheim, Germany. ${ }^{4}$ Institute of Neuropsychology and Clinical Psychology, Central Institute of Mental Health Mannheim, Medical Faculty Mannheim / Heidelberg University, Mannheim, Germany. ${ }^{5}$ Department of Clinical Psychology, Central Institute of Mental Health Mannheim, Medical Faculty Mannheim / Heidelberg University, Mannheim, Germany. 'Department of Psychiatry and Psychotherapy, Central Institute of Mental Health Mannheim, Medical Faculty Mannheim / Heidelberg University, Mannheim, Germany. 'DDepartment of Genetic Epidemiology in Psychiatry, Central Institute of Mental Health, Medical Faculty Mannheim, Heidelberg University, Mannheim, Germany. ${ }^{8}$ Institute of Psychopharmacology, Central Institute of Mental Health, Medical Faculty Mannheim / Heidelberg University, Mannheim, Germany. 'Department of Neurophysiology, Center for Biomedicine and Medical Technology 
Mannheim, Medical Faculty Mannheim / Heidelberg University, Mannheim, Germany.

Received: 30 June 2014 Accepted: 22 August 2014

Published: 9 September 2014

\section{References}

1. Zanarini MC, Frankenburg FR, Hennen J, Reich DB, Silk KR: The McLean Study of Adult Development (MSAD): overview and implications of the first six years of prospective follow-up. J Pers Disord 2005, 19:505-523.

2. Zanarini MC, Frankenburg FR, Reich DB, Fitzmaurice G: Time to attainment of recovery from borderline personality disorder and stability of recovery: a 10-year prospective follow-up study. Am J Psychiatry 2010, 167:663-667.

3. Stoffers JM, Vollm BA, Rucker G, Timmer A, Huband N, Lieb K: Psychological therapies for people with borderline personality disorder. Cochrane Database Syst Rev 2012, 8, CD005652.

4. Sanislow CA, Grilo CM, Morey LC, Bender DS, Skodol AE, Gunderson JG, Shea MT, Stout RL, Zanarini MC, McGlashan TH: Confirmatory factor analysis of DSM-IV criteria for borderline personality disorder: findings from the collaborative longitudinal personality disorders study. Am J Psychiatry 2002, 159:284-290.

5. Distel MA, Willemsen G, Ligthart L, Derom CA, Martin NG, Neale MC, Trull TJ, Boomsma DI: Genetic covariance structure of the four main features of borderline personality disorder. J Pers Disord 2010, 24:427-444.

6. Gunderson JG, Zanarini MC, Choi-Kain LW, Mitchell KS, Jang KL, Hudson JI: Family study of borderline personality disorder and its sectors of psychopathology. Arch Gen Psychiatry 2011, 68:753-762.

7. Reichborn-Kjennerud T, Ystrom E, Neale MC, Aggen SH, Mazzeo SE, Knudsen GP, Tambs K, Czajkowski NO, Kendler KS: Structure of genetic and environmental risk factors for symptoms of DSM-IV borderline personality disorder. JAMA Psychiatr 2013, 70:1206-1214.

8. Leichsenring F, Leibing E, Kruse J, New AS, Leweke F: Borderline personality disorder. Lancet 2011, 377:74-84.

9. Gross JJ: Emotion regulation: affective, cognitive, and social consequences. Psychophysiology 2002, 39:281-291.

10. Linehan MM, Kehrer CA: Borderline personality disorder. In Clinical handbook of psychological disorders: A step-by-step treatment manual. 2nd edition. New York: Guilford Press; 1993:396-441.

11. Skodol AE, Gunderson JG, Pfohl B, Widiger TA, Livesley WJ, Siever LJ: The borderline diagnosis I: psychopathology, comorbidity, and personality structure. Biol Psychiatry 2002, 51:936-950.

12. Skodol AE, Siever LJ, Livesley WJ, Gunderson JG, Pfohl B, Widiger TA: The borderline diagnosis II: biology, genetics, and clinical course. Biol Psychiatry 2002, 51:951-963.

13. Siever LJ, Torgersen S, Gunderson JG, Livesley WJ, Kendler KS: The borderline diagnosis III: identifying endophenotypes for genetic studies. Biol Psychiatry 2002, 51:964-968.

14. Tragesser SL, Solhan M, Schwartz-Mette R, Trull TJ: The role of affective instability and impulsivity in predicting future BPD features. $J$ Pers Disord 2007, 21:603-614.

15. Gratz KL, Tull MT: The relationship between emotion dysregulation and deliberate self-harm among inpatients with substance use disorders. Cognit Ther Res 2010, 34:544-553.

16. Links PS, Eynan R, Heisel MJ, Barr A, Korzekwa M, McMain S, Ball JS: Affective instability and suicidal ideation and behavior in patients with borderline personality disorder. J Pers Disord 2007, 21:72-86.

17. Yen S, Shea MT, Sanislow CA, Grilo CM, Skodol AE, Gunderson JG, McGlashan TH, Zanarini MC, Morey LC: Borderline personality disorder criteria associated with prospectively observed suicidal behavior. Am J Psychiatry 2004, 161:1296-1298.

18. Conklin CZ, Bradley R, Westen D: Affect regulation in borderline personality disorder. J Nerv Ment Dis 2006, 194:69-77.

19. Jahng S, Solhan MB, Tomko RL, Wood PK, Piasecki TM, Trull TJ: Affect and alcohol use: an ecological momentary assessment study of outpatients with borderline personality disorder. J Abnorm Psychol 2011, 120:572-584.

20. Herpertz S, Gretzer A, Steinmeyer EM, Muehlbauer V, Schuerkens A, Sass H: Affective instability and impulsivity in personality disorder. Results of an experimental study. J Affect Disord 1997, 44:31-37.
21. Ebner-Priemer UW, Welch SS, Grossman P, Reisch T, Linehan MM, Bohus M: Psychophysiological ambulatory assessment of affective dysregulation in borderline personality disorder. Psychiatry Res 2007 150:265-275.

22. Reisch T, Ebner-Priemer UW, Tschacher W, Bohus M, Linehan MM: Sequences of emotions in patients with borderline personality disorder. Acta Psychiatr Scand 2008, 118:42-48.

23. Hazlett EA, Speiser LJ, Goodman M, Roy M, Carrizal M, Wynn JK, Williams WC, Romero M, Minzenberg MJ, Siever $\sqcup$, New AS: Exaggerated affect-modulated startle during unpleasant stimuli in borderline personality disorder. Biol Psychiatry 2007, 62:250-255.

24. Santangelo P, Bohus M, Ebner-Priemer UW: Ecological momentary assessment in borderline personality disorder: a review of recent findings and methodological challenges. J Pers Disord 2014, 28:555-576

25. Santangelo P, Reinhard I, Mussgay L, Steil R, Sawitzki G, Klein C, Trull TJ, Bohus M, Ebner-Priemer UW: Specificity of affective instability in patients with borderline personality disorder compared to posttraumatic stress disorder, bulimia nervosa, and healthy controls. J Abnorm Psychol 2014, 123:258-272.

26. Rusch N, Schulz D, Valerius G, Steil R, Bohus M, Schmahl C: Disgust and implicit self-concept in women with borderline personality disorder and posttraumatic stress disorder. Eur Arch Psychiatry Clin Neurosci 2011, 261:369-376.

27. Rusch N, Lieb K, Gottler I, Hermann C, Schramm E, Richter H, Jacob GA, Corrigan PW, Bohus M: Shame and implicit self-concept in women with borderline personality disorder. Am J Psychiatry 2007, 164:500-508.

28. Stiglmayr CE, Grathwol T, Linehan MM, Ihorst G, Fahrenberg J, Bohus M: Aversive tension in patients with borderline personality disorder: a computer-based controlled field study. Acta Psychiatr Scand 2005, 111:372-379.

29. Suren P, Stoltenberg C, Bresnahan M, Hirtz D, Lie KK, Lipkin WI, Magnus P, Reichborn-Kjennerud T, Schjolberg S, Susser E, Oyen AS, Li L, Hornig M: Early growth patterns in children with autism. Epidemiology 2013, 24:660-670.

30. Ystrom E, Reichborn-Kjennerud T, Neale MC, Kendler KS: Genetic and environmental risk factors for illicit substance use and use disorders: joint analysis of self and co-twin ratings. Behav Genet 2014, 44:1-13.

31. Ludascher P, Bohus M, Lieb K, Philipsen A, Jochims A, Schmahl C: Elevated pain thresholds correlate with dissociation and aversive arousal in patients with borderline personality disorder. Psychiatry Res 2007, 149:291-296.

32. Stiglmayr CE, Ebner-Priemer UW, Bretz J, Behm R, Mohse M, Lammers CH, Anghelescu IG, Schmahl C, Schlotz W, Kleindienst N, Bohus M: Dissociative symptoms are positively related to stress in borderline personality disorder. Acta Psychiatr Scand 2008, 117:139-147.

33. Ebner-Priemer UW, Mauchnik J, Kleindienst N, Schmahl C, Peper M, Rosenthal MZ, Flor H, Bohus M: Emotional learning during dissociative states in borderline personality disorder. J Psychiatry Neurosci 2009, 34:214-222.

34. Chapman AL, Gratz KL, Brown MZ: Solving the puzzle of deliberate self-harm: the experiential avoidance model. Behav Res Ther 2006, 44:371-394.

35. Klonsky ED: The functions of deliberate self-injury: a review of the evidence. Clin Psychol Rev 2007, 27:226-239.

36. Kleindienst N, Bohus M, Ludascher P, Limberger MF, Kuenkele K, Ebner-Priemer UW, Chapman AL, Reicherzer M, Stieglitz RD, Schmahl C: Motives for nonsuicidal self-injury among women with borderline personality disorder. J Nerv Ment Dis 2008, 196:230-236.

37. Lewis M, Haviland-Jones JM, Barrett L: Handbook of Emotions.; Guilford: New York: 2008.

38. Ochsner KN, Gross JJ: The Neural Bases of Emotion and Emotion Regulation: A valuation Perspective. In Handbook of Emotion Regulation. 2nd edition. Edited by Gross JJ. New York: Guilford Press; 2014:23-42.

39. Ekman P: Emotions Revelaed: Recognizing Faces and Feelings to Improve Communication and Emotional Life. New York: Times Books; 2003.

40. Frijda N: The Emotions. Cambridge: Cambridge University Press; 1986.

41. Lazarus RS: Emotion and Adaptation. New York: Oxford University Press; 1991.

42. Neacsiu A, Linehan M, Bohus M: Dialectical Behavior Therapy: An Intervention for Emotion Dysregulation. In Handbook of Emotion Regulation. Edited by Gross JJ. New York: Guilford; 2014

43. Hayes SC, Wilson KG, Gifford EV, Follette VM, Strosahl K: Experimental avoidance and behavioral disorders: a functional dimensional approach to diagnosis and treatment. J Consult Clin Psychol 1996, 64:1152-1168. 
44. Neacsiu AD, Lungu A, Harned MS, Rizvi SL, Linehan MM: Impact of dialectical behavior therapy versus community treatment by experts on emotional experience, expression, and acceptance in borderline personality disorder. Behav Res Ther 2014, 53:47-54

45. Schramm AT, Venta A, Sharp C: The role of experiential avoidance in the association between borderline features and emotion regulation in adolescents. Pers Disord 2013, 4:138-144.

46. Meyer-Lindenberg A, Kohn PD, Kolachana B, Kippenhan S, Mclnerney-Leo A, Nussbaum R, Weinberger DR, Berman KF: Midbrain dopamine and prefrontal function in humans: interaction and modulation by COMT genotype. Nat Neurosci 2005, 8:594-596.

47. Buckholtz JW, Sust S, Tan HY, Mattay VS, Straub RE, Meyer-Lindenberg A, Weinberger DR, Callicott JH: fMRI evidence for functional epistasis between COMT and RGS4. Mol Psychiatry 2007, 12:893-895. 885.

48. Pezawas L, Meyer-Lindenberg A, Drabant EM, Verchinski BA, Munoz KE, Kolachana BS, Egan MF, Mattay VS, Hariri AR, Weinberger DR: 5-HTTLPR polymorphism impacts human cingulate-amygdala interactions: a genetic susceptibility mechanism for depression. Nat Neurosci 2005, 8:828-834

49. Meyer-Lindenberg A, Buckholtz JW, Kolachana B, Hariri AR, Pezawas L, Blasi G, Wabnitz A, Honea R, Verchinski B, Callicott JH, Egan M, Mattay V, Weinberger DR: Neural mechanisms of genetic risk for impulsivity and violence in humans. Proc Natl Acad Sci U S A 2006, 103:6269-6274.

50. Ochsner KN, Gross JJ: The cognitive control of emotion. Trends Cogn Sci 2005, 9:242-249

51. Erk S, Meyer-Lindenberg A, Schnell K, Opitz von Boberfeld C, Esslinger C, Kirsch P, Grimm O, Arnold C, Haddad L, Witt SH, Chicon S, Noethen MM Rietschel $\mathrm{M}$, Walter $\mathrm{H}$ : Brain function in carriers of a genome-wide supported bipolar disorder variant. Arch Gen Psychiatry 2010, 67:803-811.

52. Meyer-Lindenberg A, Tost $\mathrm{H}$ : Neural mechanisms of social risk for psychiatric disorders. Nat Neurosci 2012, 15:663-668.

53. Schaefer SM, Jackson DC, Davidson RJ, Aguirre GK, Kimberg DY, Thompson-Schil SL: Modulation of amygdalar activity by the conscious regulation of negative emotion. J Cogn Neurosci 2002, 14:913-921.

54. Spear LP: The adolescent brain and age-related behavioral manifestations. Neurosci Biobehav Rev 2000, 24:417-463.

55. Blakemore SJ: The social brain in adolescence. Nat Rev Neurosci 2008 , 9:267-277.

56. Calati R, Gressier F, Balestri M, Serretti A: Genetic modulation of borderline personality disorder: systematic review and meta-analysis. J Psychiatr Res 2013, 47:1275-1287.

57. Lubke GH, Laurin C, Amin N, Hottenga JJ, Willemsen G, van Grootheest G, Abdellaoui A, Karssen LC, Oostra BA, van Duijn CM, Pennina BW, Boomsma DI: Genome-wide analyses of borderline personality features. Mol Psychiatry 2014, 19:923-929

58. Tadic A, Elsasser A, Storm N, Baade U, Wagner S, Baskaya O, Lieb K, Dahmen $\mathrm{N}$ : Association analysis between gene variants of the tyrosine hydroxylase and the serotonin transporter in borderline personality disorder. World J Biol Psychiatry 2010, 11:45-58.

59. Tadic A, Victor A, Baskaya O, von Cube R, Hoch J, Kouti I, Anicker NJ, Hoppner W, Lieb K, Dahmen N: Interaction between gene variants of the serotonin transporter promoter region (5-HTTLPR) and catechol O-methyltransferase (COMT) in borderline personality disorder. Am J Med Genet B Neuropsychiatr Genet 2009, 150B:487-495.

60. Wilson ST, Stanley B, Brent DA, Oquendo MA, Huang YY, Haghighi F, Hodgkinson CA, Mann JJ: Interaction between tryptophan hydroxylase I polymorphisms and childhood abuse is associated with increased risk for borderline personality disorder in adulthood. Psychiatr Genet 2012, 22:15-24.

61. Distel MA, Middeldorp CM, Trull TJ, Derom CA, Willemsen G, Boomsma DI: Life events and borderline personality features: the influence of gene-environment interaction and gene-environment correlation Psychol Med 2011, 41:849-860.

62. Dammann G, Teschler S, Haag T, Altmuller F, Tuczek F, Dammann RH: Increased DNA methylation of neuropsychiatric genes occurs in borderline personality disorder. Epigenetics 2011, 6:1454-1462.

63. Schmahl C, Arvastson L, Tamm JA, Bohus M, Abdourahman A, Antonijevic I: Gene expression profiles in relation to tension and dissociation in borderline personality disorder. PLoS One 2013, 8:e70787.

64. New AS, Triebwasser J, Charney DS: The case for shifting borderline personality disorder to Axis I. Biol Psychiatry 2008, 64:653-659.

65. Schmahl C, Bremner JD: Neuroimaging in borderline personality disorder. J Psychiatr Res 2006, 40:419-427.
66. Ruocco AC, Amirthavasagam S, Zakzanis KK: Amygdala and hippocampal volume reductions as candidate endophenotypes for borderline personality disorder: a meta-analysis of magnetic resonance imaging studies. Psychiatry Res 2012, 201:245-252.

67. Rodrigues E, Wenzel A, Ribeiro MP, Quarantini LC, Miranda-Scippa A, de Sena EP, de Oliveira IR: Hippocampal volume in borderline personality disorder with and without comorbid posttraumatic stress disorder: a meta-analysis. Eur Psychiatry 2011, 26:452-456.

68. Niedtfeld II, Schulze L, Krause-Utz A, Demirakca T, Bohus M, Schmahl C: Voxel-based morphometry in women with borderline personality disorder with and without comorbid posttraumatic stress disorder. PLoS One 2013, 8:e65824

69. Schulz KP, Newcorn JH, McKay KE, Himelstein J, Koda VH, Siever LJ, Sharma $\checkmark$, Halperin JM: Relationship between central serotonergic function and aggression in prepubertal boys: effect of age and attention-deficit/ hyperactivity disorder. Psychiatry Res 2001, 101:1-10

70. Kuhlmann A, Bertsch K, Schmidinger I, Thomann PA, Herpertz SC: Morphometric differences in central stress-regulating structures between women with and without borderline personality disorder. J Psychiatry Neurosci 2013, 38:129-137.

71. Rossi R, Pievani M, Lorenzi M, Boccardi M, Beneduce R, Bignotti S, Borsci G, Cotelli M, Giannakopoulos P, Magni LR, Rillosi L, Rosini S, Rossi G, Frisoni GB: Structural brain features of borderline personality and bipolar disorders. Psychiatry Res 2013, 213:83-91.

72. Chanen AM, Velakoulis D, Carison K, Gaunson K, Wood SJ, Yuen HP, Yucel M, Jackson HJ, McGorry PD, Pantelis C: Orbitofrontal, amygdala and hippocampal volumes in teenagers with first-presentation borderline personality disorder. Psychiatry Res 2008, 163:116-125.

73. Whittle S, Chanen AM, Fornito A, McGorry PD, Pantelis C, Yucel M: Anterior cingulate volume in adolescents with first-presentation borderline personality disorder. Psychiatry Res 2009, 172:155-160.

74. Bender DS, Dolan RT, Skodol AE, Sanislow CA, Dyck IR, McGlashan TH, Shea MT, Zanarini MC, Oldham JM, Gunderson JG: Treatment utilization by patients with personality disorders. Am J Psychiatry 2001, 158:295-302.

75. Rusch N, Weber M, II'yasov KA, Lieb K, Ebert D, Hennig J, van Elst LT: Inferior frontal white matter microstructure and patterns of psychopathology in women with borderline personality disorder and comorbid attentiondeficit hyperactivity disorder. Neuroimage 2007, 35:738-747.

76. Rusch N, Bracht T, Kreher BW, Schnell S, Glauche V, II'yasov KA, Ebert D, Lieb K, Hennig J, Saur D, van Elst LT: Reduced interhemispheric structural connectivity between anterior cingulate cortices in borderline personality disorder. Psychiatry Res 2010, 181:151-154

77. Carrasco JL, Tajima-Pozo K, Diaz-Marsa M, Casado A, Lopez-Ibor JJ, Arrazola J, Yus M: Microstructural white matter damage at orbitofrontal areas in borderline personality disorder. J Affect Disord 2012, 139:149-153.

78. Maier-Hein KH, Brunner R, Lutz K, Henze R, Parzer P, Feigl N, Kramer J, Meinzer HP, Resch F, Stieltjes B: Disorder-specific white matter alterations in adolescent borderline personality disorder. Biol Psychiatry 2014 75:81-88

79. New AS, Carpenter DM, Perez-Rodriguez MM, Ripoll LH, Avedon J, Patil U, Hazlett EA, Goodman M: Developmental differences in diffusion tensor imaging parameters in borderline personality disorder. J Psychiatr Res 2013, 47:1101-1109.

80. van Elst LT, Thiel T, Hesslinger B, Lieb K, Bohus M, Hennig J, Ebert D: Subtle prefrontal neuropathology in a pilot magnetic resonance spectroscopy study in patients with borderline personality disorder. J Neuropsychiatry Clin Neurosci 2001, 13:511-514.

81. Hoerst M, Weber-Fahr W, Tunc-Skarka N, Ruf M, Bohus M, Schmahl C, Ende $\mathrm{G}$ : Metabolic alterations in the amygdala in borderline personality disorder: a proton magnetic resonance spectroscopy study. Biol Psychiatry 2010, 67:399-405.

82. Hoerst M, Weber-Fahr W, Tunc-Skarka N, Ruf M, Bohus M, Schmahl C, Ende $\mathrm{G}$ : Correlation of glutamate levels in the anterior cingulate cortex with self-reported impulsivity in patients with borderline personality disorder and healthy controls. Arch Gen Psychiatry 2010, 67:946-954.

83. Lieb K, Rexhausen JE, Kahl KG, Schweiger U, Philipsen A, Hellhammer DH, Bohus M: Increased diurnal salivary cortisol in women with borderline personality disorder. J Psychiatr Res 2004, 38:559-565.

84. Nater UM, Bohus M, Abbruzzese E, Ditzen B, Gaab J, Kleindienst N, Ebner-Priemer U, Mauchnik J, Ehlert U: Increased psychological and attenuated cortisol and alpha-amylase responses to acute psychosocial 
stress in female patients with borderline personality disorder. Psychoneuroendocrinology 2010, 35:1565-1572.

85. Kaess M, Hille M, Parzer P, Maser-Gluth C, Resch F, Brunner R: Alterations in the neuroendocrinological stress response to acute psychosocial stress in adolescents engaging in nonsuicidal self-injury. Psychoneuroendocrinology 2012, 37:157-161.

86. Wingenfeld K, Driessen M, Terfehr K, Schlosser N, Fernando SC, Otte C, Beblo T, Spitzer C, Lowe B, Wolf OT: Effects of cortisol on memory in women with borderline personality disorder: role of co-morbid post-traumatic stress disorder and major depression. Psychol Med 2013, 43:495-505.

87. Wingenfeld K, Driessen M, Terfehr K, Schlosser N, Fernando SC, Otte C, Beblo T, Spitzer C, Lowe B, Wolf OT: Cortisol has enhancing, rather than impairing effects on memory retrieval in PTSD. Psychoneuroendocrinology 2012, 37:1048-1056.

88. Congdon $\mathrm{E}$, Canli T: The endophenotype of impulsivity: reaching consilience through behavioral, genetic, and neuroimaging approaches. Behav Cogn Neurosci Rev 2005, 4:262-281.

89. Fineberg NA, Potenza MN, Chamberlain SR, Berlin HA, Menzies L, Bechara A, Sahakian BJ, Robbins TW, Bullmore ET, Hollander E: Probing compulsive and impulsive behaviors, from animal models to endophenotypes: a narrative review. Neuropsychopharmacology 2010, 35:591-604.

90. Coccaro EF, Siever LJ, Klar HM, Maurer G, Cochrane K, Cooper TB, Mohs RC, Davis KL: Serotonergic studies in patients with affective and personality disorders. Correlates with suicidal and impulsive aggressive behavior. Arch Gen Psychiatry 1989, 46:587-599.

91. Herpertz S, Sass H, Favazza A: Impulsivity in self-mutilative behavior: psychometric and biological findings. J Psychiatr Res 1997, 31:451-465.

92. New AS, Hazlett EA, Buchsbaum MS, Goodman M, Reynolds D, Mitropoulou V, Sprung L, Shaw RB Jr, Koenigsberg H, Platholi J, Silverman J, Siever LJ: Blunted prefrontal cortical 18fluorodeoxyglucose positron emission tomography response to meta-chlorophenylpiperazine in impulsive aggression. Arch Gen Psychiatry 2002, 59:621-629.

93. Soloff PH, Meltzer CC, Greer PJ, Constantine D, Kelly TM: A fenfluramineactivated FDG-PET study of borderline personality disorder. Biol Psychiatry 2000, 47:540-547.

94. New AS, Buchsbaum MS, Hazlett EA, Goodman M, Koenigsberg HW, Lo J, Iskander L, Newmark R, Brand J, O'Flynn K, Siever LJ: Fluoxetine increases relative metabolic rate in prefrontal cortex in impulsive aggression. Psychopharmacology (Berl) 2004, 176:451-458.

95. Meyer-Lindenberg A, Domes G, Kirsch P, Heinrichs M: Oxytocin and vasopressin in the human brain: social neuropeptides for translational medicine. Nat Rev Neurosci 2011, 12:524-538.

96. Heinrichs M, von Dawans B, Domes G: Oxytocin, vasopressin, and human social behavior. Front Neuroendocrinol 2009, 30:548-557.

97. Feldman R, Zagoory-Sharon O, Weisman O, Schneiderman I, Gordon I, Maoz R, Shalev I, Ebstein RP: Sensitive parenting is associated with plasma oxytocin and polymorphisms in the OXTR and CD38 genes. Biol Psychiatry 2012, 72:175-181.

98. Kirsch P, Esslinger C, Chen Q, Mier D, Lis S, Siddhanti S, Gruppe H, Mattay VS, Gallhofer B, Meyer-Lindenberg A: Oxytocin modulates neural circuitry for social cognition and fear in humans. J Neurosci 2005 25:11489-11493.

99 Stanley B, Siever LJ: The interpersonal dimension of borderline personality disorder: toward a neuropeptide model. Am J Psychiatry 2010, 167:24-39.

100. Bertsch K, Schmidinger I, Neumann ID, Herpertz SC: Reduced plasma oxytocin levels in female patients with borderline personality disorder. Horm Behav 2013, 63:424-429.

101. Bartz J, Simeon D, Hamilton H, Kim S, Crystal S, Braun A, Vicens V, Hollander E: Oxytocin can hinder trust and cooperation in borderline personality disorder. Soc Cogn Affect Neurosci 2011, 6:556-563.

102. Bertsch K, Gamer M, Schmidt B, Schmidinger I, Walther S, Kastel T, Schnell K, Buchel C, Domes G, Herpertz SC: Oxytocin and reduction of social threat hypersensitivity in women with borderline personality disorder. Am J Psychiatry 2013, 170:1169-1177.

103. Bandelow B, Schmahl C, Falkai P, Wedekind D: Borderline personality disorder: a dysregulation of the endogenous opioid system? Psychol Rev 2010, 117:623-636.

104. Stanley B, Sher L, Wilson S, Ekman R, Huang YY, Mann JJ: Non-suicidal self-injurious behavior, endogenous opioids and monoamine neurotransmitters. J Affect Disord 2010, 124:134-140.
105. Prossin AR, Love TM, Koeppe RA, Zubieta JK, Silk KR: Dysregulation of regional endogenous opioid function in borderline personality disorder. Am J Psychiatry 2010, 167:925-933.

106. Herpertz SC, Dietrich TM, Wenning B, Krings T, Erberich SG, Willmes K, Thron A, Sass $\mathrm{H}$ : Evidence of abnormal amygdala functioning in borderline personality disorder: a functional MRI study. Biol Psychiatry 2001, 50:292-298.

107. Donegan NH, Sanislow CA, Blumberg HP, Fulbright RK, Lacadie C, Skudlarski P, Gore JC, Olson IR, McGlashan TH, Wexler BE: Amygdala hyperreactivity in borderline personality disorder: implications for emotional dysregulation. Biol Psychiatry 2003, 54:1284-1293.

108. Niedtfeld I, Schulze L, Kirsch P, Herpertz SC, Bohus M, Schmahl C: Affect regulation and pain in borderline personality disorder: a possible link to the understanding of self-injury. Biol Psychiatry 2010, 68:383-391.

109. Schulze L, Domes G, Kruger A, Berger C, Fleischer M, Prehn K, Schmahl C, Grossmann A, Hauenstein K, Herpertz SC: Neuronal correlates of cognitive reappraisal in borderline patients with affective instability. Biol Psychiatry 2011, 69:564-573.

110. Mier D, Lis S, Esslinger C, Sauer C, Hagenhoff M, Ulferts J, Gallhofer B, Kirsch $P$ : Neuronal correlates of social cognition in borderline personality disorder. Soc Cogn Affect Neurosci 2013, 8:531-537.

111. Hazlett EA, Zhang J, New AS, Zelmanova Y, Goldstein KE, Haznedar MM, Meyerson D, Goodman M, Siever LJ, Chu KW: Potentiated amygdala response to repeated emotional pictures in borderline personality disorder. Biol Psychiatry 2012, 72:448-456.

112. Schmahl CG, Elzinga BM, Vermetten E, Sanislow C, McGlashan TH, Bremner JD: Neural correlates of memories of abandonment in women with and without borderline personality disorder. Biol Psychiatry 2003, 54:142-151.

113. Schmahl CG, Vermetten E, Elzinga BM, Bremner JD: A positron emission tomography study of memories of childhood abuse in borderline personality disorder. Biol Psychiatry 2004, 55:759-765.

114. Silbersweig D, Clarkin JF, Goldstein M, Kernberg OF, Tuescher O, Levy KN, Brendel G, Pan H, Beutel M, Pavony MT, Epstein J, Lenzenweger MF, Thomas $\mathrm{KM}$, Posner MI, Stern E: Failure of frontolimbic inhibitory function in the context of negative emotion in borderline personality disorder. Am J Psychiatry 2007, 164:1832-1841.

115. Minzenberg MJ, Fan J, New AS, Tang CY, Siever LJ: Fronto-limbic dysfunction in response to facial emotion in borderline personality disorder: an event-related fMRI study. Psychiatry Res 2007, 155:231-243.

116. Prehn K, Schulze L, Rossmann S, Berger C, Vohs K, Fleischer M, Hauenstein K, Keiper P, Domes G, Herpertz SC: Effects of emotional stimuli on working memory processes in male criminal offenders with borderline and antisocial personality disorder. World J Biol Psychiatry 2013, 14:71-78

117. New AS, Hazlett EA, Buchsbaum MS, Goodman M, Mitelman SA, Newmark R, Trisdorfer R, Haznedar MM, Koenigsberg HW, Flory J, Siever LJ: Amygdala-prefrontal disconnection in borderline personality disorder. Neuropsychopharmacology 2007, 32:1629-1640.

118. Schnell K, Herpertz SC: Effects of dialectic-behavioral-therapy on the neural correlates of affective hyperarousal in borderline personality disorder. J Psychiatr Res 2007, 41:837-847.

119. Ruocco AC, Amirthavasagam S, Choi-Kain LW, McMain SF: Neural correlates of negative emotionality in borderline personality disorder: an activation-likelihood-estimation meta-analysis. Biol Psychiatry 2013, 73:153-160

120. Bohus M, Limberger M, Ebner U, Glocker FX, Schwarz B, Wernz M, Lieb K: Pain perception during self-reported distress and calmness in patients with borderline personality disorder and self-mutilating behavior. Psychiatry Res 2000, 95:251-260.

121. Schmahl C, Greffrath W, Baumgartner U, Schlereth T, Magerl W, Philipsen A Lieb K, Bohus M, Treede RD: Differential nociceptive deficits in patients with borderline personality disorder and self-injurious behavior: laser-evoked potentials, spatial discrimination of noxious stimuli, and pain ratings. Pain 2004, 110:470-479.

122. Schmahl C, Bohus M, Esposito F, Treede RD, Di Salle F, Greffrath W, Ludaescher P, Jochims A, Lieb K, Scheffler K, Hennig J, Seifritz E: Neural correlates of antinociception in borderline personality disorder. Arch Gen Psychiatry 2006, 63:659-667.

123. Pavony MT, Lenzenweger MF: Somatosensory processing and borderline personality disorder: pain perception and a signal detection analysis of proprioception and exteroceptive sensitivity. Pers Disord 2014, 5:164-171. 
124. Cardenas-Morales L, Fladung AK, Kammer T, Schmahl C, Plener PL, Connemann BJ, Schonfeldt-Lecuona C: Exploring the affective component of pain perception during aversive stimulation in borderline personality disorder. Psychiatry Res 2011, 186:458-460.

125. Kraus A, Esposito F, Seifritz E, Di Salle F, Ruf M, Valerius G, Ludaescher P, Bohus $M$, Schmahl C: Amygdala deactivation as a neural correlate of pain processing in patients with borderline personality disorder and cooccurrent posttraumatic stress disorder. Biol Psychiatry 2009, 65:819-822.

126. Schmahl C, Ludascher P, Greffrath W, Kraus A, Valerius G, Schulze TG, Treutlein J, Rietschel M, Smolka MN, Bohus M: COMT val158met polymorphism and neural pain processing. PLOS One 2012, 7:e23658.

127. Kluetsch RC, Schmahl C, Niedtfeld I, Densmore M, Calhoun VD, Daniels J, Kraus A, Ludaescher P, Bohus M, Lanius RA: Alterations in default mode network connectivity during pain processing in borderline personality disorder. Arch Gen Psychiatry 2012, 69:993-1002.

128. Pavony MT, Lenzenweger MF: Somatosensory processing and borderline personality disorder features: a signal detection analysis of proprioception and exteroceptive sensitivity. J Pers Disord 2013, 27:208-221.

129. Hart N, McGowan J, Minati L, Critchley HD: Emotional regulation and bodily sensation: interoceptive awareness is intact in borderline personality disorder. J Pers Disord 2013, 27:506-518.

130. Niedtfeld I, Kirsch P, Schulze L, Herpertz SC, Bohus M, Schmahl C: Functional connectivity of pain-mediated affect regulation in borderline personality disorder. PLoS One 2012, 7:e33293.

131. Reitz S, Krause-Utz A, Pogatzki-Zahn EM, Ebner-Priemer U, Bohus M, Schmahl C: Stress regulation and incision in borderline personality disorder-a pilot study modeling cutting behavior. J Pers Disord 2012, 26:605-615.

132. Lanius RA, Vermetten $E$, Loewenstein RJ, Brand B, Schmahl C, Bremner JD, Spiegel D: Emotion modulation in PTSD: clinical and neurobiological evidence for a dissociative subtype. Am J Psychiatry 2010, 167:640-647.

133. Ebner-Priemer UW, Badeck S, Beckmann C, Wagner A, Feige B, Weiss I, Lieb $K$, Bohus M: Affective dysregulation and dissociative experience in female patients with borderline personality disorder: a startle response study. J Psychiatr Res 2005, 39:85-92.

134. Krause-Utz A, Oei NY, Niedtfeld I, Bohus M, Spinhoven P, Schmahl C, Elzinga BM: Influence of emotional distraction on working memory performance in borderline personality disorder. Psychol Med 2012, 42:2181-2192

135. Dyer A, Borgmann E, Feldmann RE Jr, Kleindienst N, Priebe K, Bohus M, Vocks S: Body image disturbance in patients with borderline personality disorder: impact of eating disorders and perceived childhood sexual abuse. Body Image 2013, 10:220-225.

136. Stern A: Psychoanalytic investigation of and therapy in the borderline group of neuroses. Psychoanal Q 1938, 7:467-489.

137. Bouchard S, Godbout N, Sabourin S: Sexual attitudes and activities in women with borderline personality disorder involved in romantic relationships. J Sex Marital Ther 2009, 35:106-121.

138. Bouchard S, Sabourin S: Borderline personality disorder and couple dysfunctions. Curr Psychiatry Rep 2009, 11:55-62.

139. Bouchard S, Sabourin S, Lussier Y, Villeneuve E: Relationship quality and stability in couples when one partner suffers from borderline personality disorder. J Marital Fam Ther 2009, 35:446-455.

140. Newman LK, Stevenson CS, Bergman LR, Boyce P: Borderline personality disorder, mother-infant interaction and parenting perceptions: Preliminary findings. Aust New Zeal J Psychiatr 2007, 41:598-605.

141. Hobson RP, Patrick MPH, Hobson JA, Crandell L, Bronfman E, Lyons-Ruth K: How mothers with borderline personality disorder relate to their year-old infants. Br J Psychiatry 2009, 195:325-330

142. White H, Flanagan TJ, Martin A, Silvermann D: Mother-infant interactions in women with borderline personality disorder, major depressive disorder, their co-occurrence, and healthy controls. J Reprod Infant Psychol 2011, 29:223-235.

143. Russell JJ, Moskowitz DS, Zuroff DC, Sookman D, Paris J: Stability and variability of affective experience and interpersonal behavior in borderline personality disorder. J Abnorm Psychol 2007, 116:578-588.

144. Stepp SD, Pilkonis PA, Yaggi KE, Morse JQ, Feske U: Interpersonal and emotional experiences of social interactions in borderline personality disorder. J Nerv Ment Dis 2009, 197:484-491.

145. Lis S, Bohus M: Social interaction in borderline personality disorder. Curr Psychiatry Rep 2013, 15:338.
146. Barnow S, Stopsack M, Grabe HJ, Meinke C, Spitzer C, Kronmuller K, Sieswerda S: Interpersonal evaluation bias in borderline personality disorder. Behav Res Ther 2009, 47:359-365.

147. Williams KD, Jarvis B: Cyberball: a program for use in research on interpersonal ostracism and acceptance. Behav Res Methods 2006, 38:174-180.

148. Ruocco AC, Medaglia JD, Tinker JR, Ayaz H, Forman EM, Newman CF, Williams JM, Hillary FG, Platek SM, Onaral B, Chute DL: Medial prefrontal cortex hyperactivation during social exclusion in borderline personality disorder. Psychiatry Res 2010, 181:233-236.

149. Renneberg B, Herm K, Hahn A, Staebler K, Lammers CH, Roepke S: Perception of social participation in borderline personality disorder. Clin Psychol Psychother 2012, 19:473-480.

150. Staebler K, Renneberg B, Stopsack M, Fiedler P, Weiler M, Roepke S: Facial emotional expression in reaction to social exclusion in borderline personality disorder. Psychol Med 2011, 41:1929-1938.

151. Domsalla M, Koppe G, Niedtfeld I, Vollstadt-Klein S, Schmahl C, Bohus M, Lis S: Cerebral processing of social rejection in patients with borderline personality disorder. Soc Cogn Affect Neurosci 2013, Epub ahead of print.

152. Hess YD, Pickett CL: Social rejection and self- versus other-awareness. J Exp Soc Psychol 2010, 46:453-456.

153. Moor BG, Guroglu B, Op de Macks ZA, Rombouts SA, van der Molen MW Crone EA: Social exclusion and punishment of excluders: neural correlates and developmental trajectories. Neuroimage 2012, 59:708-717.

154. Wagner AW, Linehan MM: Facial expression recognition ability among women with borderline personality disorder: implications for emotion regulation? J Pers Disord 1999, 13:329-344

155. Lynch TR, Rosenthal MZ, Kosson DS, Cheavens JS, Lejuez CW, Blair RJ: Heightened sensitivity to facial expressions of emotion in borderline personality disorder. Emotion 2006, 6:647-655.

156. Schulze L, Domes G, Koppen D, Herpertz SC: Enhanced detection of emotional facial expressions in borderline personality disorder. Psychopathology 2013, 46:217-224.

157. Veague HB, Hooley JM: Enhanced sensitivity and response bias for male anger in women with borderline personality disorder. Psychiatry Res 2014, 215:687-693

158. Unoka Z, Fogd D, Fuzy M, Csukly G: Misreading the facial signs: specific impairments and error patterns in recognition of facial emotions with negative valence in borderline personality disorder. Psychiatry Res 2011 189:419-425.

159. Robin M, Pham-Scottez A, Curt F, Dugre-Le Bigre C, Speranza M, Sapinho D, Corcos M, Berthoz S, Kedia G: Decreased sensitivity to facial emotions in adolescents with borderline personality disorder. Psychiatry Res 2012, 200:417-421.

160. Daros AR, Zakzanis KK, Ruocco AC: Facial emotion recognition in borderline personality disorder. Psychol Med 2013, 43:1953-1963.

161. Fertuck EA, Grinband J, Stanley B: Facial trust appraisal negatively biased in borderline personality disorder. Psychiatry Res 2013, 207:195-202.

162. Hagenhoff M, Franzen N, Gerstner L, Koppe G, Sammer G, Netter P, Gallhofer B, Lis S: Reduced sensitivity to emotional facial expressions in borderline personality disorder: effects of emotional valence and intensity. J Pers Disord 2013, 27:19-35.

163. Franzen N, Hagenhoff M, Baer N, Schmidt A, Mier D, Sammer G, Gallhofer B, Kirsch P, Lis S: Superior 'theory of mind' in borderline personality disorder: an analysis of interaction behavior in a virtual trust game. Psychiatry Res 2011, 187:224-233.

164. Herpertz SC, Bertsch K: The social-cognitive basis of personality disorders. Curr Opin Psychiatry 2014, 27:73-77.

165. Staebler K, Helbing E, Rosenbach C, Renneberg B: Rejection sensitivity and borderline personality disorder. Clin Psychol Psychother 2011, 18:275-283

166. Domes G, Czieschnek D, Weidler F, Berger C, Fast K, Herpertz SC: Recognition of facial affect in borderline personality disorder. J Pers Disord 2008, 22:135-147.

167. King-Casas B, Sharp C, Lomax-Bream L, Lohrenz T, Fonagy P, Montague PR: The rupture and repair of cooperation in borderline personality disorder. Science 2008, 321:806-810.

168. Unoka Z, Seres I, Aspan N, Bodi N, Keri S: Trust game reveals restricted interpersonal transactions in patients with borderline personality disorder. J Pers Disord 2009, 23:399-409.

169. Fonagy $P$, Bateman A: The development of borderline personality disorder-a mentalizing model. J Pers Disord 2008, 22:4-21. 
170. Bateman A, Fonagy P: 8-year follow-up of patients treated for borderline personality disorder: mentalization-based treatment versus treatment as usual. Am J Psychiatry 2008, 165:631-638.

171. Choi-Kain LW, Gunderson JG: Mentalization: ontogeny, assessment, and application in the treatment of borderline personality disorder. Am J Psychiatry 2008, 165:1127-1135.

172. Fertuck EA, Jekal A, Song I, Wyman B, Morris MC, Wilson ST, Brodsky BS, Stanley B: Enhanced 'Reading the Mind in the Eyes' in borderline personality disorder compared to healthy controls. Psychol Med 2009, 39:1979-1988.

173. Harari H, Shamay-Tsoory SG, Ravid M, Levkovitz Y: Double dissociation between cognitive and affective empathy in borderline personality disorder. Psychiatry Res 2010, 175:277-279.

174. Dziobek I, Preissler S, Grozdanovic Z, Heuser I, Heekeren HR, Roepke S: Neuronal correlates of altered empathy and social cognition in borderline personality disorder. Neuroimage 2011, 57:539-548.

175. Roepke S, Vater A, Preissler S, Heekeren HR, Dziobek I: Social cognition in borderline personality disorder. Front Neurosci 2012, 6:195

176. Jeung $H$, Herpertz SC: Impairments of interpersonal functioning: empathy and intimacy in borderline personality disorder. Psychopathology in press.

177. Salgado JV, Sandner G: A critical overview of animal models of psychiatric disorders: challenges and perspectives. Rev Bras Psiquiatr 2013, 35(Suppl 2):S77-S81.

178. Koch M: Animal models in schizophrenia research. Neuroforum 2002, 8:236-244

179. Whishaw IQ, Metz GA, Kolb B, Pellis SM: Accelerated nervous system development contributes to behavioral efficiency in the laboratory mouse: a behavioral review and theoretical proposal. Dev Psychobio 2001, 39:151-170.

180. Winstanley CA: The utility of rat models of impulsivity in developing pharmacotherapies for impulse control disorders. Br J Pharmacol 2011 164:1301-1321.

181. Silverman JL, Yang M, Lord C, Crawley JN: Behavioural phenotyping assays for mouse models of autism. Nat Rev Neurosci 2010, 11:490-502.

182. Grant FC, Mackintosh JH: A comparison of some of the social postures of some common laboratory rodents. Behavior 1963, 21:246-259.

183. Schneider P, Hannusch C, Schmahl C, Bohus M, Spanagel R, Schneider M: Adolescent peer-rejection persistently alters pain perception and CB1 receptor expression in female rats. Eur Neuropsychopharmacol 2014, 24:290-301.

184. Kirrane RM, Mitropoulou V, Nunn M, Silverman J, Siever LJ: Physostigmine and cognition in schizotypal personality disorder. Schizophr Res 2001, 48:1-5.

185 Douglas LA, Varlinskaya El, Spear LP: Rewarding properties of social interactions in adolescent and adult male and female rats: impact of social versus isolate housing of subjects and partners. Dev Psychobiol 2004, 45:153-162.

186. Vanderschuren LJ, Niesink RJ, Van Ree JM: The neurobiology of social play behavior in rats. Neurosci Biobehav Rev 1997, 21:309-326.

187. Battle CL, Shea MT, Johnson DM, Yen S, Zlotnick C, Zanarini MC, Sanislow CA, Skodol AE, Gunderson JG, Grilo CM, McGlashan Th, Morey LC: Childhood maltreatment associated with adult personality disorders: findings from the collaborative longitudinal personality disorders study. J Pers Disord 2004, 18:193-211.

188. Ball JS, Links PS: Borderline personality disorder and childhood trauma: evidence for a causal relationship. Curr Psychiatry Rep 2009, 11:63-68.

189. Berrettini WH: Genetic bases for endophenotypes in psychiatric disorders. Dialogues Clin Neurosci 2005, 7:95-101.

190. Zanarini MC, Frankenburg FR, Reich DB, Fitzmaurice G: Attainment and stability of sustained symptomatic remission and recovery among patients with borderline personality disorder and axis II comparison subjects: a 16-year prospective follow-up study. Am J Psychiatry 2012, 169:476-483.

191. Zanarini MC, Frankenburg FR, Reich DB, Silk KR, Hudson Jl, McSweeney LB: The subsyndromal phenomenology of borderline personality disorder: a 10-year follow-up study. Am J Psychiatry 2007, 164:929-935.

192. Morgan TA, Chelminski I, Young D, Dalrymple K, Zimmerman M: Differences between older and younger adults with borderline personality disorder on clinical presentation and impairment. J Psychiatr Res 2013, 47:1507-1513.
193. Lieb K, Zanarini MC, Schmahl C, Linehan MM, Bohus M: Borderline personality disorder. Lancet 2004, 364:453-461.

194. Steele H, Siever L: An attachment perspective on borderline personality disorder: advances in gene-environment considerations. Curr Psychiatry Rep 2010, 12:61-67.

195. Bredy TW, Grant RJ, Champagne DL, Meaney MJ: Maternal care influences neuronal survival in the hippocampus of the rat. Eur J Neurosci 2003, 18:2903-2909.

196. Liu D, Diorio J, Day JC, Francis DD, Meaney MJ: Maternal care, hippocampal synaptogenesis and cognitive development in rats. Nat Neurosci 2000, 3:799-806.

197. Champagne FA, Curley JP: How social experiences influence the brain. Curr Opin Neurobiol 2005, 15:704-709.

198. Maestripieri D, McCormack K, Lindell SG, Higley JD, Sanchez MM: Influence of parenting style on the offspring's behaviour and CSF monoamine metabolite levels in crossfostered and noncrossfostered female rhesus macaques. Behav Brain Res 2006, 175:90-95.

199. Almasy L, Blangero J: Endophenotypes as quantitative risk factors for psychiatric disease: rationale and study design. Am J Med Genet 2001, 105:42-44.

200. Gottesman II, Gould TD: The endophenotype concept in psychiatry: etymology and strategic intentions. Am J Psychiatry 2003, 160:636-645.

doi:10.1186/2051-6673-1-12

Cite this article as: Schmahl et al:: Mechanisms of disturbed emotion processing and social interaction in borderline personality disorder: state of knowledge and research agenda of the German Clinical Research Unit. Borderline Personality Disorder and Emotion Dysregulation 2014 1:12.

\section{Submit your next manuscript to BioMed Central and take full advantage of:}

- Convenient online submission

- Thorough peer review

- No space constraints or color figure charges

- Immediate publication on acceptance

- Inclusion in PubMed, CAS, Scopus and Google Scholar

- Research which is freely available for redistribution

Submit your manuscript at www.biomedcentral.com/submit
C Biomed Central 